\title{
Seven-year follow-up of heroin addicts: abstinence and continued use compared
}

\author{
EDNA OPPENHEIMER, GERRY V STIMSON, ANTHONY THORLEY
}

British Medical fournal, 1979, 2, 627-630

\section{Summary and conclusions}

Data from a seven-year follow-up study of drug addicts were examined to see whether there were any differences between those who had stopped using opiates and those who had continued to use them. Information about the addicts when they first entered the study in 1969 was also reviewed to determine whether any of their characteristics would have predicted whether they would stop using opiates or continue. Those who had stopped using opiates by 1976-7 were more likely than the continuing addicts to have a job and legitimate scource of income, to be in good health, and to have a stable address and less likely to have problems with the law or contact with addicts. In 1969, however, there were few differences between those who eventually stopped using drugs and those who continued, though the former group were younger, had a shorter period of heroin use, and had worked less since they became addicted.

Over the seven years' follow-up the addicts who stopped taking drugs changed most, while those who stayed on opiates changed their life-style very little.

\section{Introduction}

There is now considerable evidence that many opiate addicts stop using drugs after a period of addiction. In a previous

\footnotetext{
Addiction Research Unit, Institute of Psychiatry, London SE5 8AF EDNA OPPENHEIMER, BA, DASS, research social worker

University of London, Goldsmiths' College, London SE14 6NW GERRY V STIMSON, PHD, senior lecturer in sociology

Parkwood House, Alcohol and Drug Dependence Unit, St Nicholas's Hospital, Newcastle upon Tyne

ANTHONY THORLEY, MB, MRCPSYCH, consultant psychiatrist
}

report on the present study ${ }^{1}$ we noted that over a third of a cohort of addicts known to be injecting heroin in London in 1968 had stopped using opiates seven years later.

Earlier studies have suggested an association between remaining abstinent and working ${ }^{2}$ and living in a family. ${ }^{3}$ There is no evidence that ex-addicts develop mental illnesses, though Vaillant noted a "fairly high" incidence of alcoholism. ${ }^{3}$

Several attempts to try to identify aspects of the behaviour, personality, or lifestyle of addicts that might predict whether or not they would stop using opiates have produced generally equivocal results. Chapple et $a l^{*}$ suggested that abstinence is associated with the chronicity of addiction and that the prognosis is better for the early "pre-chronic" addict who has had a short history of addiction, no previous admission for drug taking, and a withdrawal from drugs within the first year of treatment. Another study ${ }^{5}$ found an association between voluntary abstinence from opiates and length of heroin use. The longer a person had used heroin the more likely he was to have had at least one long voluntary abstention. In the study which has taken the longest time perspective $(20 \text { years })^{3}$ only three variables differentiated the best and worst outcome for addicts. A greater proportion of those who eventually became abstinent had been employed for four or more years before their first admission to hospital for drug abuse, had been raised in the same culture as their parents, and had been married at some time. Vaillant suggests that these distinguishing factors support the hypothesis that chronic addiction is a substitute for stable human relationships.

These reports generally suggest that cessation of opiate use is associated with some changes in lifestyle. Nevertheless, it is far from clear what these changes might be and in what precise ways abstainers differ from those who continue to use drugs. Attempts to look at prognostic factors do not give a coherent picture either. This paper is a further attempt to examine some of these problems.

\section{Methods}

The data for this paper came from a seven- to eight-year follow-up study of heroin addicts. From June 1976 to November 1977 we followed-up 128 people ( 93 men and 35 women) who in 1969 were selected as a representative sample of people prescribed heroin at 
London drug dependency clinics. All the addicts in this sample experienced the effects of the changes in British drug policies in the late 1960s which led to the establishment of drug dependency clinics. These clinics have varied enormously in their approaches to the problem of addiction. Some clinicians were willing to prescribe heroin and even cocaine. Others believed in the importance of switching patients to methadone ampoules or methadone linctus. Thus clinics varied in whether they saw their treatment goal as abstinence or stable maintenance.

The people in the sample were first interviewed in 1969 and were then followed-up through Home Office records of addict notifications. ${ }^{7-9}$ The 1976-7 follow-up was the first attempt to personally recontact the entire sample. We succeeded in following-up $97 \%$ of the original sample ${ }^{1}$ : personal contact was made with 107 people, of whom 97 were interviewed in full and 10 were interviewed in part with some reliance on contemporary secondary sources of information-for example, staff of clinics and voluntary agencies, spouses, parents. The interview consisted of structured and semi-structured questions which were taperecorded. Personal contact was not made with two people but current information was obtained from contemporary secondary sources. There was no contact or current information on four people. Fifteen had died $(12 \%)$. The average length of follow-up was 7 years 7 months, with a range of 6 years 9 months to 8 years 3 months. The average age at follow-up was $32 \cdot 7$ years.

We compared two groups: the users $\left(61,48_{0}^{\circ}\right)$, who were still using opiates at follow-up, and the abstainers $\left(40,31^{\circ}{ }_{0}\right)$, who had stopped using opiates. We excluded those who were dead, in prison, or whose drug use was uncertain at follow-up. Details of drug use and outcome have been given elsewhere. ${ }^{1}$ Twenty of the users and 10 of the abstainers were women. We made three comparisons: firstly, to see whether there were major differences between abstainers and users in behaviour and health at the end of the follow-up; secondly, to see whether there were differences in the behaviour of the two groups when they were first seen which might have predicted the outcome; and, thirdly, a comparison of the people within each group over time to examine the nature and direction of longitudinal changes. The information used here is from the follow-up interview in 1976-7 and from the first interview in 1969.

\section{Results}

\section{DIFFERENCES BETWEEN ABSTAINERS AND USERS OF OPIATES}

There were several major differences between those who had stopped using opiates and those who continued to use them. The general trend was one of overall improvement in major social, economic, and personal dimensions for those who no longer used opiates compared with those who continued.

Drugs (table I)-By definition no opiate drugs were used by the abstainers in the 28 days before the follow-up interview. The mean

TABLE I-Drug use in 28 days before follow-up: differences between abstainers and users at follow-up. Results are numbers (percentages) of patients

\begin{tabular}{|c|c|c|c|c|c|c|c|c|c|}
\hline \multirow[b]{3}{*}{ Opiates } & \multicolumn{4}{|c|}{ Users $(n=61)$} & \multicolumn{5}{|c|}{ Abstainers $(n=40)$} \\
\hline & \multicolumn{2}{|c|}{ Prescribed } & \multicolumn{2}{|c|}{ Used } & \multicolumn{3}{|c|}{ Prescribed } & \multirow{2}{*}{ Used $t$} & \multirow{2}{*}{$\frac{P}{0.05}$} \\
\hline & 55 & $(90)$ & 61 & $(100)$ & 0 & & 0 & & \\
\hline Tranquillisers & 14 & (24) & 17 & $(29)^{*}$ & 6 & (16) & 8 & $(21)^{*}$ & \\
\hline Amphetamines & 5 & (9) & 19 & (33)* & 0 & $(0)$ & 0 & & 0.05 \\
\hline Cocaine & 3 & (5) & 6 & (10) & 0 & & 1 & (3) & \\
\hline Hypnotics & 12 & (20) & .22 & (37)* & 3 & (8) & 4 & (10) & 0.05 \\
\hline Cannabis & 0 & & 25 & $(43)^{*}$ & 0 & & 19 & $(49)^{*}$ & 0.05 \\
\hline Drugs obtained illegally & & & 26 & $(43) *$ & 0 & & 5 & (12) & \\
\hline $\begin{array}{l}\text { Alcohol: } \\
100 \mathrm{ml} \text { daily in past } 28\end{array}$ & days & & 4 & (7) & & & 1 & (3) & \\
\hline No days exceeding 100 & $\mathrm{ml}$ & & 23 & $(40) *$ & & & 22 & $(61)^{*}$ & \\
\hline
\end{tabular}

*Numbers $<1, \mathrm{~N}<40$ : percentages based on known numbers.

+ Significance level, users versus abstainers on drugs used, $\chi^{2}$ test

length of time since last physical dependence $( \pm S D)$ was $4 \cdot 7 \pm 2 \cdot 3$ years (range 0.8 to 8.3 years). All those in the user group had used opiates in the previous 28 days; 55 attended drug dependency clinics and received daily prescriptions for heroin or methadone, or both. (Prescription data for this group have been given. ${ }^{1}$ ) There were six people who used opiates but did not receive clinic prescriptions and they relied on illegal supplies. Fifteen of those attending clinics had obtained opiates illegally in addition to their prescription. There were considerable differences between the groups in their use of non-opiate drugs. People in both groups had used some psychotropic drugs in the 28 days before follow-up. The abstainers used few drugs, while those still using opiates used more drugs from both legal and illegal sources. There was no significant difference, however, between the groups in respect to cannabis, which was used by just under half the people in both groups. There was no evidence that the abstainers had transferred their previous dependence on opiates to a new dependence on other substances. Sixteen $\left(40^{\circ}{ }_{0}\right)$ of the abstainers had been totally free of drug use in the previous 28 days. Similarly, there was no evidence that previous dependence on opiates had been transferred to dependence on alcohol or that opiate addicts of long standing, who perhaps no longer experienced much euphoria from opiates, turned to alcohol for its special effects. Only four of the drug users and one of the abstainers reported heavy drinking (defined as drinking $100 \mathrm{ml}$ or more of ethanol daily in the previous 28 days). More of the abstainers reported light drinking (defined as no days in previous 28 days when drinking exceeded $100 \mathrm{ml}$ of ethanol), though the differences between the groups was not statistically significant. This suggests, perhaps, that those who abstain from drugs are similar in their drinking patterns to the general population.

Health (table II) - No medical examination was undertaken. Selfrating of health in the previous two weeks showed that significantly more abstainers than users rated their health as good or excellent. Predictably, none of the abstainers reported having had conditions such as abscesses, septiceamia, or hepatitis, which are normally associated with drug use.

TABLE II-Differences between abstainers and users at follow-up. Results are numbers (percentages) of patients

\begin{tabular}{lccccc}
\hline \multicolumn{1}{c}{ Health } & Users $(\mathrm{n}=61)$ & & \multicolumn{2}{c}{$\begin{array}{c}\text { Abstainers } \\
(\mathrm{N}=40)\end{array}$} & $P$ \\
\hline $\begin{array}{l}\text { Good or excellent } \\
\text { Poor or very poor }\end{array}$ & 29 & $(51)^{*}$ & 28 & $(\mathbf{7 6})^{*} 0.05$ \\
In the last three months: & 10 & $(18)^{*}$ & 4 & $(11)^{*}$ \\
$\quad$ Abscess at injection sites & 8 & $(13)$ & 0 & \\
Abscess elsewhere & 5 & $(8)$ & 0 & \\
Septicaemia & 1 & $(2)$ & 0 & \\
Hepatitis & 2 & $(3)$ & 0 & \\
\hline
\end{tabular}

*Numbers $<61, \mathrm{~N}<40$ : percentages based on known numbers.

Crime (table III) -At follow-up abstainers were significantly less "involved" with the law (on remand, suspended sentence, conditional discharge, or probation): only one person among the abstainers was involved with the law as opposed to $14(23 \%)$ of the users. Similarly, significantly fewer of the abstainers admitted breaking the law in any way with respect to shoplifting, illegal possession of drugs, or selling drugs in the previous three months.

TABLE III-Crime: differences between abstainers and users at follow-up. Results are numbers (percentages) of patients

\begin{tabular}{|c|c|c|c|c|c|}
\hline \multirow[b]{2}{*}{$\begin{array}{l}\text { On remand, suspended sentence, conditional } \\
\text { discharge or probation } \\
\text { Recent criminal activities: }\end{array}$} & \multicolumn{2}{|c|}{$\begin{array}{c}\text { Users } \\
(\mathrm{n}=61)\end{array}$} & \multicolumn{2}{|c|}{$\begin{array}{c}\text { Abstainers } \\
(\mathrm{n}=\mathbf{4 0 )}\end{array}$} & \multirow{2}{*}{$\frac{P}{0.05}$} \\
\hline & 14 & (23) & 1 & 3 & \\
\hline Shoplifting & 12 & $(21)^{*}$ & 0 & & 0.05 \\
\hline Illegal possession of drugs & 42 & $(72)^{*}$ & 17 & $(46) *$ & 0.05 \\
\hline Obtained things by false pretences & 6 & $(11)^{*}$ & 0 & $(8) *$ & \\
\hline $\begin{array}{l}\text { Received stolen goods } \\
\text { Sold drugs }\end{array}$ & $\begin{array}{r}7 \\
14\end{array}$ & $\begin{array}{l}(12)^{*} \\
(24)^{*}\end{array}$ & $\begin{array}{l}3 \\
1\end{array}$ & $\begin{array}{l}(8)^{*} \\
(3)^{*}\end{array}$ & 0.05 \\
\hline One or more of above & 42 & $(72)^{*}$ & $\cdot 19$ & $(51)^{*}$ & 0.05 \\
\hline
\end{tabular}

*Numbers $61, \mathrm{~N}<40$ : percentages based on known numbers.

Work and income (table IV)-Significantly more of the abstainers were employed at follow-up: $83^{\circ}$ o compared with $62^{\circ}$, of the users. Only $18^{\circ}{ }_{0}$ of the abstainers and $40^{\circ}$ of of the users had not worked at all in the previous 13 weeks. Abstainers were less likely to receive some form of social security or unemployment benefit, and less likely to support themselves by "hustling" (borrowing, shoplifting, stealing, selling drugs, borrowing money from friends).

Contact with addicts-Those who had stopped using drugs had tended to change their friends. Most of the abstainers $(89 \%)$ reported no close addict friends, while only $44^{\circ}$ o of the users said that they 
TABLE IV-Employment: differences between abstainers and users at follow-up. Results are numbers (percentages) of patients

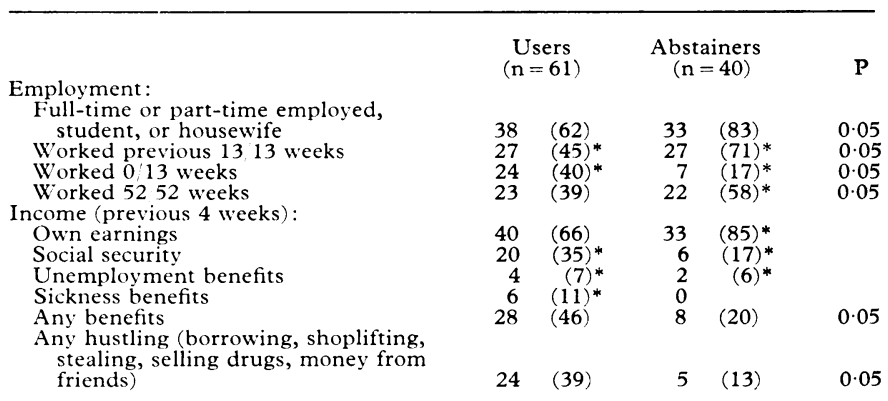

*Numbers $61,-40$ : percentages based on known numbers.

had no addict friends. None of the abstainers had visited Piccadilly or any other centre of drug trading in the last week, while $25 \%$ of the users said that they had done so. In general, the abstainers seemed to live in more permanent accommodation than the users: $95 \%$ had a permanent address compared with $79^{\circ}{ }_{0}$ of the users.

\section{DIFFERENCES BETWEEN PRESENT USERS AND ABSTAINERS IN 1969}

The two groups were compared using data from the 1969 interview on status over the preceeding one or three-month periods and background characteristics. On most variables there were no significant differences (see table V). There were only four items for which we found significant differences between the two groups. Those who abstained at follow-up were, in 1969, likely: to be younger than the

TABLE V-Differences between present abstainers and present users at and before first interview in 1969

\begin{tabular}{|c|c|c|c|c|c|}
\hline \multicolumn{3}{|l|}{ Status in 1969} & $\begin{array}{c}0 \text { of users } \\
\quad(n=61)\end{array}$ & $\begin{array}{c}\text { oof } \\
\text { abstainers } \\
(n=40)\end{array}$ & $\mathbf{P}$ \\
\hline \multicolumn{6}{|c|}{ Drug use: } \\
\hline \multicolumn{3}{|c|}{ Heroin dose prescribed of $110 \mathrm{mg}$} & 56 & 45 & \\
\hline & $\ldots$ & . & 41 & 51 & \\
\hline Injected in presence of addicts & $\therefore$ & $\cdots$ & 58 & 50 & \\
\hline \multirow{2}{*}{\multicolumn{6}{|c|}{ Health (in previous 13 weeks)* }} \\
\hline & & & & & \\
\hline Hepatitis . . . . $\quad \ldots$ & . & . & 8 & 5 & \\
\hline Septicaemia & $\cdots$ & $\cdots$ & 14 & 18 & \\
\hline \multirow{2}{*}{\multicolumn{6}{|c|}{ Criminal activities*: }} \\
\hline & & & & & \\
\hline Shoplifting .. . . . . & . & . & 22 & 36 & \\
\hline Illegal possession of drugs & $\cdots$ & $\therefore$ & 67 & 77 & \\
\hline Received stolen goods & $\therefore$ & $\because$ & 10 & 30 & \\
\hline Obtained things by false preten & ces & $\therefore$ & 8 & 23 & \\
\hline \multirow{2}{*}{\multicolumn{6}{|c|}{ Involvement with addicts*: ${ }^{*}$}} \\
\hline & & & & & \\
\hline Visited Piccadilly .. .. & $\ldots$ & $\ldots$ & 48 & 55 & \\
\hline Three close friends addicts & $\therefore$ & $\therefore$ & 31 & 19 & \\
\hline Knows $\quad 41$ addicts & . & $\therefore$ & 50 & 47 & \\
\hline \multirow{2}{*}{\multicolumn{6}{|c|}{$\begin{array}{l}\text { Employment*: } \\
\text { Full-time or part-time employed, student }\end{array}$}} \\
\hline & & & & & \\
\hline 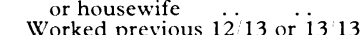 & & & 57 & 47 & \\
\hline \multirow{2}{*}{\multicolumn{6}{|c|}{ Income*: }} \\
\hline & & & & & \\
\hline $\begin{array}{l}\text { Awn earning } \\
\text { Any benefits }\end{array}$ & $\cdots$ & $\because$ & $\begin{array}{l}62 \\
25\end{array}$ & $\begin{array}{l}41 \\
43\end{array}$ & \\
\hline $\begin{array}{ccc}\text { Any oenecial security } & \ldots & \ldots\end{array}$ & $\because$ & $\because$ & 21 & 35 & \\
\hline Unemployment benefits & $\therefore$ & $\therefore$ & 2 & 6 & \\
\hline Sickness benefits & $\because$ & . & 8 & 18 & \\
\hline Borrowing .. .. & $\ldots$ & . & 19 & 23 & \\
\hline Stealing $\ldots$ & . & . & 12 & 9 & \\
\hline Selling things & $\therefore$ & $\therefore$ & 24 & 19 & \\
\hline Money from friends & $\therefore$ & $\because$ & 22 & 19 & \\
\hline Shoplifting .. . . & $\therefore$ & $\therefore$ & 12 & 12 & \\
\hline Selling drugs $\quad \ldots$ & $\therefore$ & $\therefore$ & 22 & 24 & \\
\hline \multicolumn{6}{|l|}{ Personal background known in 1969 : } \\
\hline Female $\ldots$ & .. & .. & 33 & 25 & \\
\hline Age $23 \quad \ldots \quad \ldots$ & & $\therefore$ & 61 & 33 & 0.05 \\
\hline Used heroin for 7 years up to & 1969 & & 65 & 32 & 0.05 \\
\hline \multicolumn{3}{|c|}{ Proportion of time worked from first heroin } & 18 & 26 & 0.05 \\
\hline \multicolumn{3}{|c|}{$\begin{array}{l}\text { use to } 1969 \\
\text { Abstinent from heroin one or more times }\end{array}$} & 48 & 26 & 0.05 \\
\hline \multirow{2}{*}{\multicolumn{3}{|c|}{$\begin{array}{l}\text { before } 1969 \\
\text { In hospital one or more times before } 1969\end{array}$}} & 3 & 8 & \\
\hline & & & 57 & 56 & \\
\hline \multirow{2}{*}{\multicolumn{3}{|c|}{$\begin{array}{l}\text { Left school } 15 \text { years } \\
\text { Separation from mother (or father) before }\end{array}$}} & 48 & 31 & \\
\hline & & & & & \\
\hline $16 \ldots$ & .. & .. & $26(36)$ & $18(28)$ & \\
\hline Married by $1969 \ldots$ & $\therefore$ & $\therefore$ & 67 & 76 & \\
\hline First used heroin at age 19 & $\therefore$ & $\therefore$ & 45 & 43 & \\
\hline First drank alcohol at age 15 & 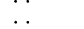 & $\therefore$ & 46 & 37 & \\
\hline 3 convictions to 1969 & .. & . & 36 & 42 & \\
\hline
\end{tabular}

* Variables also used for longitudinal comparison, see text. users; to have had a shorter length of heroin use before coming to a drug dependency clinic; to have worked a smaller proportion of time since they began to use heroin (and, related to this, a smaller proportion of time in the 13 weeks before the 1969 interview).

\section{CHANGES IN BEHAVIOUR BETWEEN 1969 and AND 1976}

We know that the abstainers were similar to the users in 1969 , but that they were different in 1976. To see whether the abstainers had changed and in what ways we examined each group for longitudinal changes, with a view to asking whether each group's pattern of behaviour in 1976 was the same as or different from that in 1969.

Those who still used opiates were virtually the same in 1976 as in 1969: there had been hardly any overall changes as a group, for better or for worse. The only change found concerned the cleanliness with which addicts injected, which followed change in the direction of cleaner injection techniques from 1969 to 1976. On all the other variables examined, noted with an asterisk on table $\mathrm{V}$, there were no significant changes between 1969 and 1976. For the abstainers there had been large changes in all the areas of behaviour examined in this paper. The same people who in 1969 were really no different from the rest of the sample were at follow-up changed in almost every variable checked. The picture which emerged was that the differences between the abstainers and users in 1976 could be explained only by the changes having occurred in the abstainer group between 1969 and 1976.

\section{Discussion}

In this study we took a sample of people who in 1969 were addicted to heroin and receiving prescriptions for heroin from London drug dependency clinics. Seven years later when they were reinterviewed we found that $31 \%$ (40) were no longer using heroin or other opiates and were living in the community. They were compared with a group of people from the original sample who continued to use opiates.

We have indicated that in crude behavioural terms there were major differences between those who continued to use opiates and those who stopped. Those who stopped led a generally more socially stable life: they were less likely to have problems with the law or report any criminal activity and more likely to be employed and have legitimate sources of income, to be living in stable accommodation, to be in little contact with addicts, and to be in good or excellent health. All the evidence suggests that those who said they abstained from opiates in fact did so. They were little concerned in legal or illegal nonopiate drug use. Thus they had not turned to other drugs (including alcohol) as a substitute for their former opiate dependence.

We found little evidence which is useful for predicting who might become abstinent and who is likely to continue using drugs, for our analysis showed very little difference in 1969 between the addicts who later stopped, and those who continued taking opiates. The fact that those who eventually abstained were younger and had a shorter period of heroin use is broadly in line with other research evidence. The other distinguishing factor, that they had worked less since their addiction up until 1969 than those who were still using opiates in 1976 was an unexpected finding and differed from that of Vaillant. ${ }^{6}$ One explanation may be that it was younger more recently addicted and perhaps more socially disorganised addicts - that is, unemployed-who attracted the greatest therapeutic endeavour from clinic staff. Looking at changes from 1969 to 1976 we found that it was those who had stopped using opiates who had changed most, with those who had continued using opiates showing few changes in behaviour. Those who stayed on opiates, as a group, fared no better and no worse than when they were first interviewed in 1969.

Thanks are due to Griffith Edwards, Colin Taylor, Margaret Sheehan, Richard Hartnoll, Rolf Wille, and Jacqueline May and to 
the consultants and staff of the drug dependence clinics, who have been generous in their help over the years.
${ }^{4}$ Chapple, P A L, Somekh, D E, and Taylor, M E, British fournal of Addiction, 1972, 67, 33.

5 Waldorf, D, Social Problems, 1970, 18, 228.

${ }^{6}$ Vaillant, G E, Archives of General Psychiatry, 1973, 20, 237.

7 Stimson, G V, and Ogborne, A C, Lancet, 1970, 1, 1163.

Ogborne, A C, and Stimson, G V, International fournal of Addiction, 1975 10,1061

9 Thorley, A, Oppenheimer, E, and Stimson, G V, British fournal of Psychiatry, 1977, 130, 565.

(Accepted 26 fuly 1979)

\title{
New mechanical aid to physiotherapy in cystic fibrosis
}

\author{
K A FLOWER, R I EDEN, L LOMAX, N M MANN, JEAN BURGESS
}

British Medical fournal, 1979, 2, 630-631

\section{Summary and conclusions}

The force of impact and frequency of percussion by physiotherapists and parents of children with cystic fibrosis were analysed on a special test rig and incorporated in a prototype percussor. In adult volunteers and cadavers a maximum intrathoracic pressure could be achieved by a critical frequency of mechanical percussion which was higher than that reached by physiotherapists and parents. Consequently the percussor was redesigned to operate at this optimum frequency. It was then discovered that if the percussor was pressed firmly enough against the chest, this maximum intrathoracic pressure could be indicated by quivering of the voice. In a continuing study of intrathoracic pressures obtained mechanically and manually the Salford percussor produced higher pressures than the physiotherapists' and maintained them constantly, while the physiotherapists' efforts and results varied from one to another. Hospital and domiciliary use of the percussor have shown it to help in the first stage of the physiotherapy routine for patients with cystic fibrosis.

The percussor should enable adolescents and adults to treat themselves and encourage twice-daily and more effective chest treatment. It is easy to apply and its speed and efficiency should enable parents to improve the quality of their chest therapy for younger children at home. Its long-term benefits are difficult to assess because of the nature of the disease.

\section{Introduction}

Physiotherapy is a vital part of the management which has extended the life expectancy of patients with cystic fibrosis. ${ }^{1-3}$

\footnotetext{
Department of Aeronautical and Mechanical Engineering, University of Salford, Salford M5 4WT

K A FLOWER, MSC, PHD, lecturer

R I EDEN, $M B$, CHB, research student

L LOMAX, BSC, research studen

Royal Manchester Children's Hospital, Pendlebury M27 1HA

N M MANN, MD, FRCPED, consultant paediatrician

JEAN BURGESS, MCSP, SRP, senior physiotherapist
}

The main components of physiotherapy to segments of the lung during postural drainage are percussion, assisted panting, squeezing, and shaking of the chest. The secretions loosened in this way are removed by spontaneous or controlled coughing. The best chest treatment is given by physiotherapists in hospitals and their outpatient departments but most chest therapy is given at home. Capable and conscientious parents, however, may be handicapped if they have more than one child with cystic fibrosis or are themselves unwell. Less co-operative parents cannot be relied on to apply twice-daily and efficient chest treatment. When children reach adolescence they may resent their dependence on their family and other people for treatment, which can then become haphazard. Mechanical aids to chest treatment should meet some of these needs to allow a more independent life.

\section{Patients and methods}

Experimental apparatus was built to measure the speed and the force of impact of percussion of physiotherapists and parents of children with cystic fibrosis. The test rig consisted of a mild steel beam supported by adjustable end-mounts. A curved block representing the chest was fixed on to the centre of the beam. A transducer was mounted under the curved block and its output fed to a recorder. The compliance of the steel bar was adjusted so that it was judged by the physiotherapists to resemble the compliance of a chest. The "chest" was then percussed by physiotherapists and parents with their usual technique. The trace from the recorder was analysed for speed and force of percussion. The results enabled a first generation of prototype percussors to be developed which were driven by air to reproduce the speed and force of percussion. These failed, however, because the air compressors proved ineffective.

At this time, the relation of the frequency of percussion to the intrathoracic pressure produced by it was investigated. The tracheas of 22 adult cadavers (aged 44 to 68 years) were intubated with Foley catheters. A low-pressure transducer was connected to the catheter and to a recorder. Nine volunteers (aged 18 to 38 years) swallowed oesophageal balloons and by similar transducer techniques the intrathoracic pressures created by percussion were recorded. We discovered that the curves obtained were identical and a maximum intrathoracic pressure could be achieved by a critical frequency of percussion signified by vibration of the voice (fig 1). Therefore, a second generation of prototype percussors was designed but based on a reciprocating movement found in a portable but modified jig saw. This enabled the speed of percussion to be increased to the optimum value discovered in the intrathoracic pressure experiments. A $68-\mathrm{mm}$ diameter rubber cup with a depression of $6 \mathrm{~mm}$ fitted to the percussor shaft delivered the percussion.

In a second and continuing study of intrathoracic pressures during physiotherapy on an examination couch the percussor was compared with three physiotherapists and the pressures recorded in the Wilhel- 